Estuarine, Coastal and Shelf Science

AUGUST 2003; 57(5-6) : 1127-1137

Archimer http://www.ifremer.fr/docelec/ Archive Institutionnelle de l'Ifremer

\title{
In situ video and diffraction analysis of marine particles
}

\author{
Michel Lunven $^{*, a}$, P. Gentien ${ }^{\mathrm{b}}$, K. Kononen ${ }^{\mathrm{c}}, \mathrm{E}$. Le Gall ${ }^{\mathrm{a}}$ and M. M. Daniélou ${ }^{\mathrm{a}}$
}

a IFREMER, Centre de Brest, DEL/EC/PP, B.P. 70, 29280, Brest, France

${ }^{\text {b }}$ Crema, B.P. 5, 17137, L'Houmeau, France

${ }^{\text {c }}$ Academy of Finland, Vilhonvuorenkatu 6, P.O. Box 99, 00501, Helsinki, Finland

*: Corresponding author : mlunven@ifremer.fr

\begin{abstract}
:
A design for a new underwater video-system to detect and observe suspended particles is presented. Particles are collected and isolated in a rectangular box where they are highly illuminated by a white light plane. The total field of view is determined. The camera, equipped with a remote controlled zoom, can resolve particles sizes ranging from $25 \mu \mathrm{m}$ to several millimetres. Real-time image analyses are therefore performed. Particle counts and size spectra are calculated and displayed. Total light intensity scattered by the illuminated particles is closely related to the back-scattering values determined by an optical back-scatter sensor. A particle size analyser using diffraction analysis is associated to this video-system on a custom profiler. Hydrological parameters are measured by a standard CTD probe associated to a chlorophyll sensor. Results are acquired and graphically presented in real time. This custom profiler presents numerous advantages in oceanographic research. Two examples of its use in different coastal areas are presented. In an estuary, temporal evolution of particle characteristics was described in relation to the tide cycle. While the video-system allows direct visualization and characterization of the largest particles, the particle-size analyser performs precise quantification of the finest ones. It was shown that the two methods were in accordance for quantification of large aggregates, which were observed around slack tide when salinity decreased. Video analyses cannot be performed above $25 \mathrm{mg} \mathrm{I}^{-1}$ dry weight equivalent. The system reliability, resolution and limits were also demonstrated during a cruise in the Gulf of Finland. A typical profile is presented here showing different layers, one characterized by the association of heterotrophic flagellates and detritals, and another dominated by zooplankton, the surface layer being characterized by cyanobacterial colonies. Video associated to diffraction analyses allows the study of flocculation processes in estuaries and a detailed description of thin layers.
\end{abstract}

Keywords: in situ measurement; suspended matter; flocculation; fine scale distribution; image analysis 


\section{Introduction}

Understanding the spatial and temporal variability of suspended particle populations is essential to many fields of oceanographic research including sediment transport and ecology. In estuaries, tidally induced variations in current speed and direction lead to large variations in particle concentration through re-suspension and deposition. Depending both on hydrodynamical and hydrological parameters, particles can flocculate and constitute large aggregates, which are maintained by inter-particle forces (Kranck, 1993; Trent et al., 1978; Eisma et al., 1986; Bale \& Morris, 1987). Generally, vertical and horizontal particle diffusion depends not only on the particle population characteristics but also on particles interactions leading to aggregation. Many studies have shown that the vertical density gradient often governs the vertical distribution of particle populations in the water column. For instance, phytoplankton and zooplankton species have often been observed in very thin layers (Vilivic et al., 1989; Owen, 1989; Dekshenieks et al., 2001) i.e. when biological and physical conditions allow optimal growth and accumulation of their populations. Understanding relationships between particle distribution and environmental parameters (e.g. hydrology) appears to be necessary in order to better understand the structure and functioning of a given ecosystem.

Precise studies on suspended matter distribution in seawater require direct in situ quantification of the particle characteristics. In situ particle sizing by laser diffraction is a relatively recent development which has been accurately implemented by several research teams (Agrawal \& Pottsmith, 1989; Gentien et al., 1995, Bale \& Morris, 1996). Over the last years, the importance of video systems has also increased (Eisma et al., 1990; Gorsky et al., 1992, 2000; Fennessy et al., 1994; Van Leussen \& Corneliss, 1996; Davis et al., 1996; Knowles \& Wells, 1998; Tiselius, 1998; Dyer \& Manning, 1999; Katz et al., 1999; Widder et al., 1999; Franks \& Jaffe, 2001). The optical and mechanical designs of these developed systems varied depending on the objectives and the quantity and quality of the particles under study.

In two previous studies (Gentien et al., 1995; Lunven \& Gentien, 2000), we have reported cases where large organic aggregates presumably introduced biases in measurements of particle population distribution. Sampling of these aggregates being very difficult, confirmation of their occurrence can only be performed through direct video observation. The design of a new underwater videomicroscope is presented here with applications to estuarine and coastal environments. Recorded images are analysed using video imaging techniques to obtain particle size measurements. This video-system is associated to a particle sizer by diffraction analysis. These two methods are complementary, permitting both the quantification and qualification of major particle populations.

\section{Materials and methods}

In its complete configuration (Fig. 1), the new custom profiler integrates a CILAS (Marcoussis, FRANCE) particle size analyser (PSA) (Gentien et al., 1995), a SBE25 CTD probe (Sea-Bird Electronics, Washington, USA), a video-system (Fig. 2) and a SBE 32 carousel water sampler (Sea-Bird Electronics, Washington, USA). 


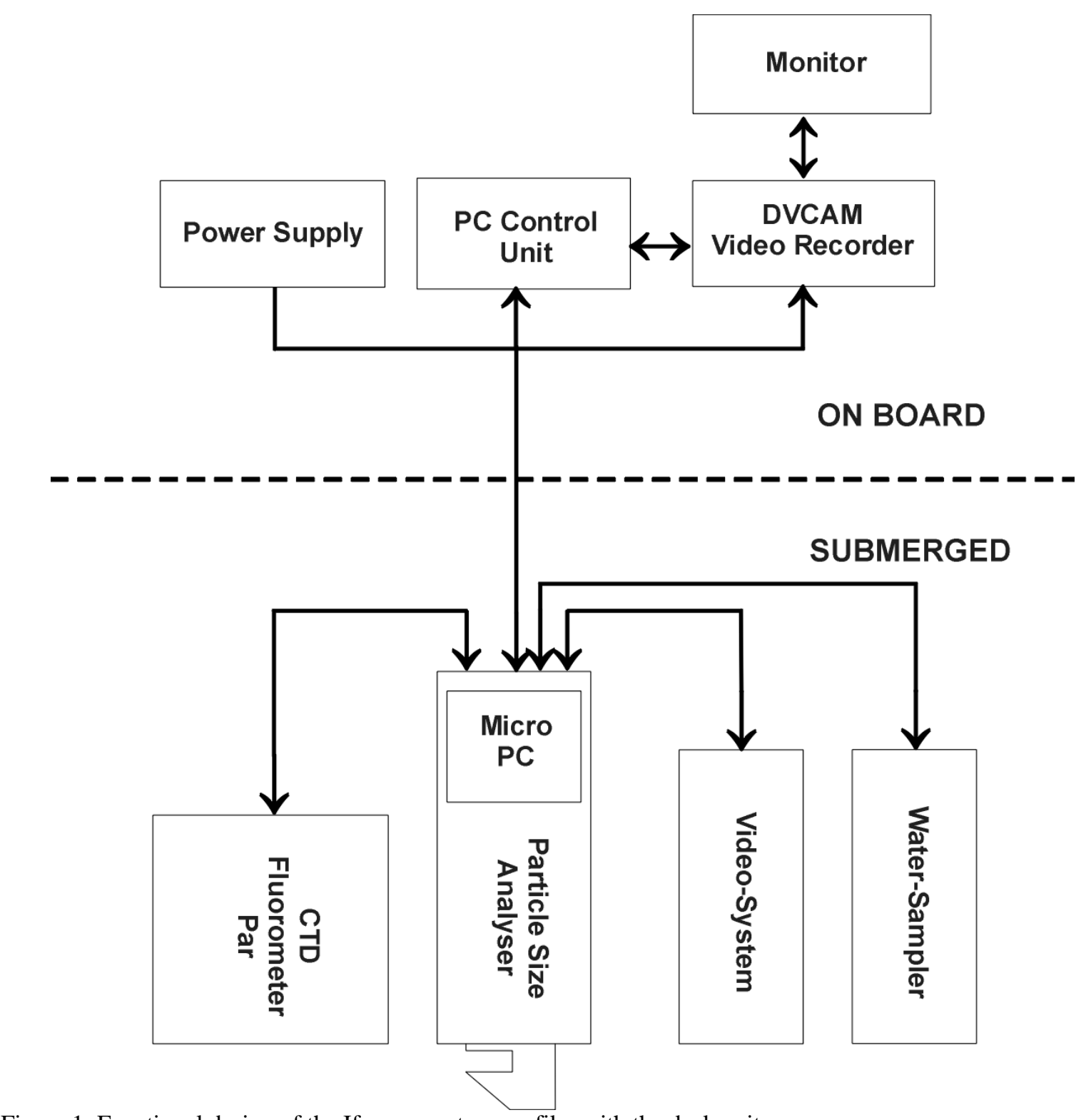

Figure 1: Functional design of the Ifremer custom profiler with the deck unit

The particle size analyser (PSA) and the CTD probe.

Based on diffraction pattern analysis, the particle size analyser (PSA) measures the total volume of particles present in an 8-ml free flow cell and their size distribution over 30 classes from 0.7 to $400 \mu \mathrm{m}$ (for a complete description, see Gentien et al., 1995). The particles remain in the medium, thus allowing the upmost accuracy of their characterization. From the particle distribution size spectra and the total volume of particles, PSA data examination can be made by grouping different size classes. This method enables the quantification of typical particle populations: sedimentary and primary particles, phytoplankton species, microflocs and macroflocs (sensu Eisma, 1986). This profiler acquires in real time parameters such as depth, temperature, salinity, chlorophyll-like fluorescence, optical back-scattering for estimation of suspended sediment concentration and photosynthetically available radiation (PAR). 


\section{The Videomicroscope}

Capture/Stilling Chamber. The mechanism for collecting and isolating the particles to be analysed consists in a rectangular PVC black box closed by a motorised door (Fig. 2). In order to create a stable dark-field illumination independent from ambient light, it is necessary to observe particles in the dark. Furthermore, this technique allows to use a low cost camera by dampening turbulence and also permits recognition of animal movements. Its dimensions $(21 * 21 * 24 \mathrm{~cm})$ are sufficiently large so that the field of view is comparatively small, thus limiting possible effects in size distribution due to breakage of flocs against the wall. The particles are trapped in this chamber by opening and closing the door remotely from the ship. Movement of the door is slow $\left(8 \mathrm{~cm} \mathrm{~s}^{-1}\right)$ and particles movement induced by door closure decays in ca. $20 \mathrm{~s}$. as observed in laboratory still conditions. This design presents several advantages. Firstly, particles trapped into the box are considerably slowed. Secondly, they are highly illuminated as they pass through a stable and uniform light sheet which defines a sampling zone of known volume. Therefore, they are clearly seen with high contrast illumination against the black field. However, due to movements of the profiler in the water, particles displacements inside the box still remains.

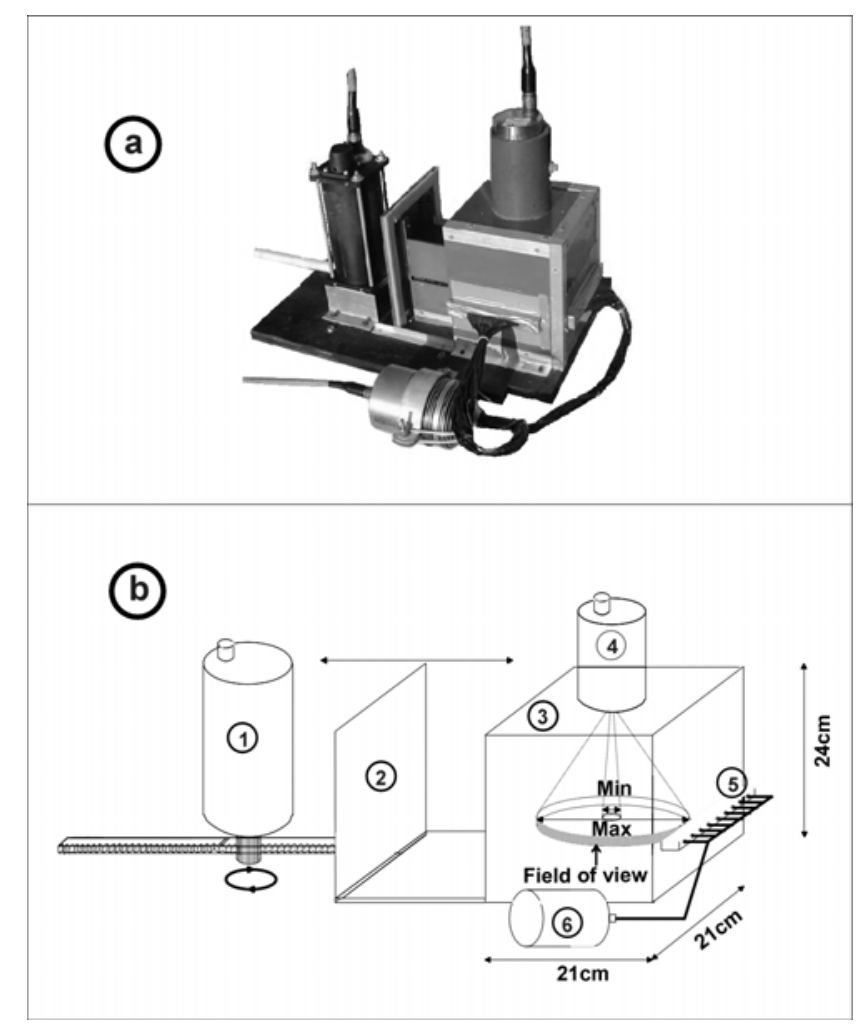

Figure 2: Photograph (a) and Line Drawing (b) of the Video-System with its main elements: (a.1): the Electric Motor; (a.2): the Sliding Door; (a.3): the Capture/Stilling Chamber; (a.4): the CCD Camera; (a.5): the Light Source; (a.6): the Optic Fibers.

Light source. The lighting system consists of one $100 \mathrm{~W}$ halide lamp focused on an optic fibre network producing a white light plane. A rectangular diaphragm placed in front of the light source limits its angular dispersion. Laboratory tank tests have shown that this set-up results in an $1.5 \mathrm{~cm}$ thick illuminated sheet centered on the focal plane of the camera. The volume of water visualised is a function of the optical zoom of the camera. This illuminated volume is 
positioned $18 \mathrm{~cm}$ from the camera in the confining box. Because of the light source homogeneity, the image background is uniform allowing a good visualisation of the particles.

Camera. A Sony CCD XVC 660 Camera housed by EXAVISION (Nîmes, France) and equipped with a remote controlled zoom (max magnification x12) is used to acquire images which are then digitized (768 x 576 pixels x 256 grey levels - Black: 0 - White: 255) by a Corona framegrabber (Matrox, Darval, Canada).

Optical calibration. The use of the video-system for quantitative analysis requires precise determination of the volume sampled. The system calibration is performed by measuring the relative size of one pixel from the grabbed image. Laboratory calibrations by mean of a test card positioned under the camera gives the relationship between the pixel size and the zoom value. Depth of field was quantified with the same method. The video-system is therefore calibrated in terms of volume and depends on the zoom magnification (Akiba \& Kakui, 2000), acquired in real time (Table I). This system allows to change the magnification during a water profile. An operational compromise is generally made and allows the detection of particles $\sim 65 \mu \mathrm{m}$, considering that two contiguous pixels are necessary to resolve one particle. However, when needed, for detailed observations, it is possible to change the zoom magnification in the range described in Table I. Since this magnification is acquired in real time and included in the image processing, all the measurements are comparable.

Computed values. During data acquisition process, the images are treated following usual imagery techniques (Matrox Imagery Library, Darval, Canada). The image is binarized using a threshold value which is kept constant during a whole series of measurements in order to obtain comparable results. This threshold value depends usually on the lamp intensity and, to a lesser extent, on the zoom magnification and on the particles size distribution. No filtering or image enhancements are performed on the original images so as to obtain comparative quantitative results from the whole set of treated images (Milligan, 1996). By applying this threshold level to the grey-scale image, it is possible to extract the particle contours and to compute the number of particles per volume. The particle size distribution is calculated from the measurement of the equivalent spherical diameter (ESD) of each object. Total particle volume per ml. (in ppm) can then be computed from the total particles volume and the volume of water represented by the digitized area. In the case of measurements performed in the bottom layer, the influence of particles size distribution and of the total amount of suspended matter becomes critical so that the threshold value must be adapted by periods. Without using a threshold on the initial image matrix, a Mean Grey Level Value (MGLV) can be computed, being directly related to light intensity scattered at $90^{\circ}$. MGLV is interpreted as a nephelometric value, integrating total suspended matter including small particles, undetected by image analysis procedures. During high sediment load periods, the background level may increase to values which prevent from contouring large particles. Empirically, a threshold value of 80 in the grey-scale for the background has been chosen. Above this limit, no image analysis could be performed. For each samples, at least 10 images are grabbed or for low particle loads, at least 400 particles are counted. Particle renewal in the observed volume depends on particles movements which are mainly due to the profiler's. Those are highly dependent from uncontrolled factors such as waves, ship's pitching and rolling. Therefore, it is difficult to determine the degree of auto-correlation in series of images. From movies observations, we fixed a 2 s. sampling interval as a good compromise for statistical estimations. Imaging results and sensors data are stored in ASCII format; thus, they can be imported and treated under any spreadsheet editor. 
Table I: SpecifNications of selected zoom magnifications with their corresponding Volume of View $\left(\mathrm{mm}^{3}\right)$. Bold figures correspond to generally used parameters for the apparatus.

\begin{tabular}{cccccc}
\hline $\begin{array}{c}\text { Optical } \\
\begin{array}{c}\text { Magnification } \\
\text { of Lens }\end{array}\end{array}$ & $\begin{array}{c}\text { Field of } \\
\text { View(mm) }\end{array}$ & $\begin{array}{c}\text { Focal View } \\
(\mathrm{mm})\end{array}$ & $\begin{array}{c}\text { Volume of } \\
\text { View }\left(\mathrm{mm}^{3}\right)\end{array}$ & $\begin{array}{c}\text { Resolving Power } \\
(3 \text { contiguous } \\
\text { pixel) } \\
(\mu \mathrm{m})\end{array}$ & $\begin{array}{c}\text { Sample } \\
\text { Volume } \\
\text { Ratio (\%) }\end{array}$ \\
\hline X 1 & 130 X 105 & 20 & 273000 & 276 & 2.6 \\
X 6 & 60.8 X 49.2 & 18 & 53844 & 129 & 0.50 \\
$\begin{array}{c}\text { Commonly } \\
\text { used : X 8.70 }\end{array}$ & $\mathbf{3 0 . 9}$ X 25.0 & $\mathbf{1 5}$ & $\mathbf{1 1 5 8 8}$ & $\mathbf{6 5 . 1}$ & $\mathbf{0 . 1 1}$ \\
X 12 & 11.9 X 9.6 & 8 & 914 & 25.2 & 0.01 \\
\hline
\end{tabular}

The deck unit - Field data acquisition and image analysis

The deck unit allows on-line acquisition of data from the sensors, Capture/Stilling Chamber control, recording and treatment of the video images. The parts of the deck unit are a DVCAM video recorder and a monitor, a remote control for the camera, a power supply for the immersed instruments and finally, a computer equipped with the frame-grabber card. This deck unit is connected to the profiler by a cable which enables data, video and power supply transmission. A Micro-PC computer equipped with expansion cards (Octagon, Westminster, USA) is integrated into the PSA housing. It allows synchronisation of both the commands and the data acquisition between the immersed equipment and the deck computer via an RS422 link. On deck, a custom software running on a PC computer simultaneously drives the PSA, the CTD probe, the DVCAM recorder and the Capture/Stilling Chamber. It allows real time data acquisition, graphical visualisation and storage. Means, variances and relationships between studied parameters are calculated and plotted, allowing rapid diagnostics. The deck unit allows sampling by bottle closure with appropriate flagging in data files. The maximal deployment depth is limited by the camera housing, which is rated to 100 meters depth.

\section{Profiling mode}

The descent at a speed of $0.25 \mathrm{~m} \mathrm{~s}^{-1}$ down to the lower depth allows a rapid determination of the hydrological structures of the water column. When operated in real time, this system is adapted to the detection and the characterisation of specific water layers (fluorescence maximum, pycnocline, aggregates, zooplankton patches, cyanobacteria colonies...). The video-system is not used during the lowering of the probe. From the detected layers, finest measurements are performed at depth steps when the probe is raised. Video observations are then displayed and recorded on deck.

\section{Mooring mode}

The equipment is anchored on the sea bed or moored at a given water depth. Times series are acquired from the sensors (PSA, CTD), while regular trapping of particles enables observation, qualification and quantification of the larger particles. This configuration is useful to investigate tidally induced variations of particle characteristics in estuarine and coastal areas during periods of up to 6 hours. 


\section{Results and discussion}

Temporal variability of particle populations in a macrotidal estuary

In the Elorn estuary $\left(48^{\circ} 24^{\prime} 30 \mathrm{~N}, 004^{\circ} 20^{\prime} 48 \mathrm{~W}\right.$, Bay of Brest, Britanny, France), the sediments are of alluvial origin and are mainly composed of quartz, mica, chlorite, kaolinite and illite. The equipment was lowered to one meter above sea floor. Data were acquired over 5 hours, on October 14, 1996, over the ebb-tide. During the experiment, the tidal height decreased from $6.5 \mathrm{~m}$ to $3 \mathrm{~m}$. The low salinity values observed one hour before low tide were caused by the advection of fresh water from the Elorn River (Fig. 3.a). Current speed measurements (S4, InterOcean, San Diego, USA) were also performed over the measurement period. During the ebb-tide, maximum current velocities reached $40 \mathrm{~cm} \mathrm{~s}^{-1}$, 4 hours before low tide (Lunven \& Gentien, 2000). The period of low current velocity ( $<15 \mathrm{~cm} \mathrm{~s}^{-1}$ ) occurred 1 to 1.5 hour prior to low tide.
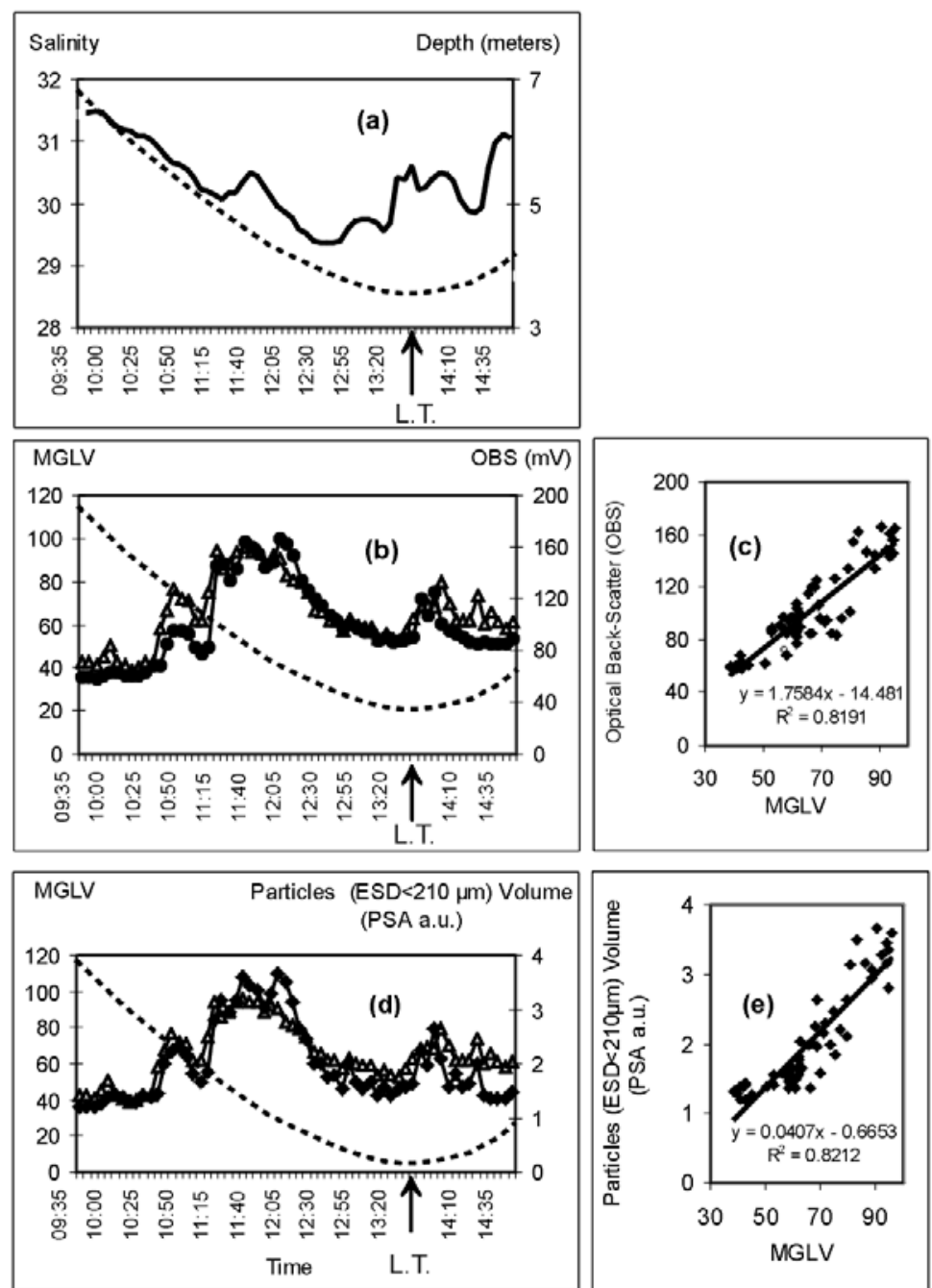

Figure 3: Time series over an ebb-tidal cycle in the Elorn estuary on October 14, 1996 : (a): Salinity (continuous line) and depth (dotted line). (b, c): Mean Grey Level Value (MGLV; $\mathbb{L} d)$ ), Optical back-scatter (OBS; \& $)$ and the corresponding relationship. (d, e): Mean Grey Level Value (MGLV; 미), Particle Size Analyser (PSA; $\left.\Xi^{\circ}\right)$ volume for particles smaller than $210 \mu \mathrm{m}$ and the corresponding relationship. The line drawing (----) corresponds to the sampling depth i.e. the tidal cycle. LT : Low Tide. 
Suspended Particulate Matter Concentration. In order to validate the sampling and measuring method by the Closing/Stilling Chamber system, temporal variations in MGLV is compared to OBS temporal variation (Fig. 3.b,c), PSA volume estimation (data not shown) and PSA volume estimation for particles smaller than $210 \mu$ m-diameter (Fig. 3.d,e). A regression curve is also presented comparing each type of measurement, showing a close relationship between the OBS measurements and MGLV values. From the PSA measurements, it appears that the MGLV was linearly related to the cumulated volume of smaller particles. No significant relationship was found between total volume of particles estimated by PSA and MGLV (data not shown) since back-scatter underestimates large particles contribution (Lunven \& Gentien, 2000). Many studies have demonstrated that standard back-scatter output varies as a function of the particle size. For examples, with calibrated glass grain, an inverse relationship was found between OBS measurements and the grain size (Conner \& de Wiser, 1992). Previous studies have shown an underestimation of $150 \%$ by OBS due to flocs abundance (Gibbs \& Wolanski, 1992). In coastal zones, Jago and Bull (2000) quantified the errors of suspended particulate matter flux determined by transmissiometer and laser sizer. They showed that the SPM concentrations have to be derived from transmissiometer values by adopting a two-part correlation according to the particle characteristics.

The concordance between MGLV and OBS measurements validates the sampling and measuring method employed through the Capture/Stilling Chamber concept.

Video analyses. Temporal variability in particle concentrations and characteristics is high and depends on hydrodynamics: low concentrations represented by small particles were indeed recorded at the beginning of the tide cycle (Fig 4.a.1), large particles were sampled just after the maximum current speed (Fig 4.a.2), and the slack tide period revealed a global decrease in the particle load (Fig. 4.a.3). As described in the method section, due to a large increase in small particles $(<100 \mu \mathrm{m})$, no image analysis could be performed between 11:10 and 12:05 am. For the two periods of image analysis, total particle volume was calculated by the video method and compared to PSA measurements (Fig. 4.b). The flocculation period occurring around slack tide was well described by the video-system and the suspended matter volume quantified by video analyses was in accordance with the PSA values (Fig. 4.c). 


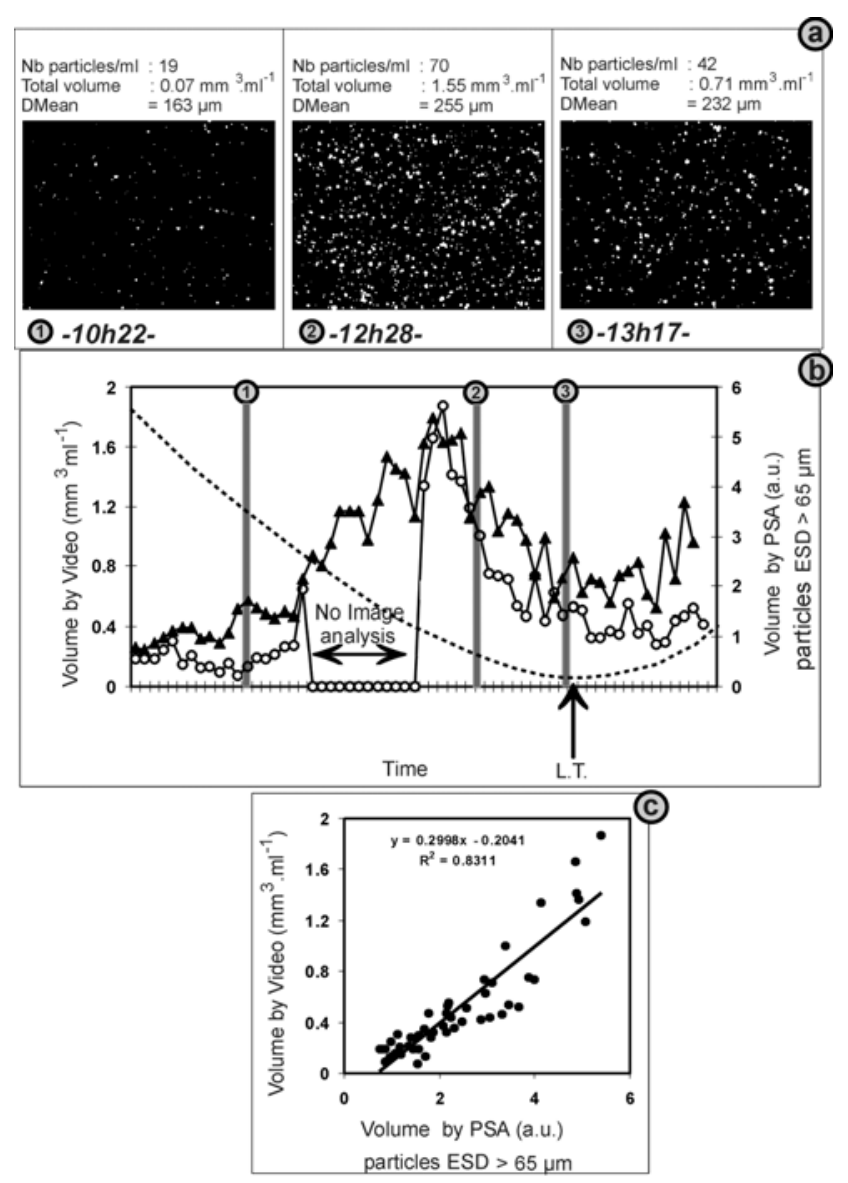

Figure 4: (a.1, а.2, a.3): Three in situ digitized images from the videorecording in Elorn estuary with their corresponding computed data. (b): Time series: Volume by PSA for particles larger than $65 \mu \mathrm{m}$ (o), Volume by Video (i) and sampling depth (dotted line) over an ebb-tidal cycle in the Elorn estuary on October 14, 1996. (c): Relationship between particle volume obtained by video and diffraction (ESD > $65 \mu \mathrm{m})$.

This time series highlights the limits of the video-system which could not accurately describe and quantify the increase in particles between 11:10 and 12:05 am. Particle resolution by image analysis was in fact limited by the concentration of suspended matter and its organisation (sedimentary particles, flocs, microflocs, flocculates). Corresponding to high back-scatter values, the high light level scattered by the abundance of small particles in the confining box was accurately received by the CCD camera as proved by the Mean Grey Level Value criteria (MGLV; Fig. 3.b). However, these small particles could not be individually resolved by image analysis. The degree of flocculation is indeed critical in determining the ability of the video-system to resolve particles. In estuaries, the video method is more particularly adapted for the detection, count and measurement of large size particles such as microflocs $(65-125 \mu \mathrm{m})$ and macroflocs $(>125 \mu \mathrm{m}$; sensu Eisma, 1986). Particle volume measurements by both diffraction and video analysis showed a good concordance. This can be considered as an in situ validation of the Capture/Stilling Chamber method for the investigation of the particles size characteristics by video. Scene observations and video measurements did not reveal any influence of the video-system mechanical design on the particle size distribution. As mentioned in the method section, the chamber dimensions and the door closure speed were calculated so as to limit a possible breakage of the particles against the walls. However, the equipment was not tested in high hydrodynamical conditions. In the Elbe estuary, using a specific in situ video equipment for particle size measurements, Milligan (1996) has shown biases due to flocs break-up at current speeds above $100 \mathrm{~cm} \mathrm{~s}^{-1}$. 
From our field calibrations during the high suspended matter period with no image analysis, we found that SPM was higher than $25 \mathrm{mg} \mathrm{l}^{-1}$ dry weight.

From all these observations, it appears that over the ebb-tide period, when current velocities increased after slack tide, fine particles $(<100 \mu \mathrm{m})$ became more abundant. This results in a peak concentration 3 to 4 hours after slack tide. Our different sensors appeared efficient in quantifying and qualifying particle populations in this estuarine field. From 10:00 to 11:30 am, small particles increased in number as seen by PSA measurements. This could be due to the re-suspension and transport of sedimentary particles from the sea-bed associated with the breaking apart of large flocs with the increasing shear, when current velocity increased. On the contrary, PSA results and video images presented a large particle peak around 12:30 am, i.e. 1 - 2 hours after the fine particle peak. Over this period, while the number of fine particles decreased, the number of large particles increased. This appearance of large particles could be explained by flocculation of the finest ones which disappeared from the suspension.

These results are consistent with previous works performed in the same area (Lunven \& Gentien, 2000). The latter authors have indeed shown that organic aggregates appeared under low current and low salinity conditions, around the end of ebb-tide. The processes of aggregation and disaggregation of organic material with sedimentary and primary particles depends on hydrodynamical and hydrological conditions. For instance, over the ebb-tide period, salinity decreased as the fresh water inflow from the river increased. As shown in figure 5, low salinity is related to higher concentrations of suspended macroflocs quantified by the video-system. Because of their low density, flocs with high organic content have low settling rate, so that they can remain longer in suspension (Dyer \& Manning, 1999). Our results are also in agreement with Eisma and Li (1993) who reported an increase in the average size of the flocculates together with a decrease in current speed.

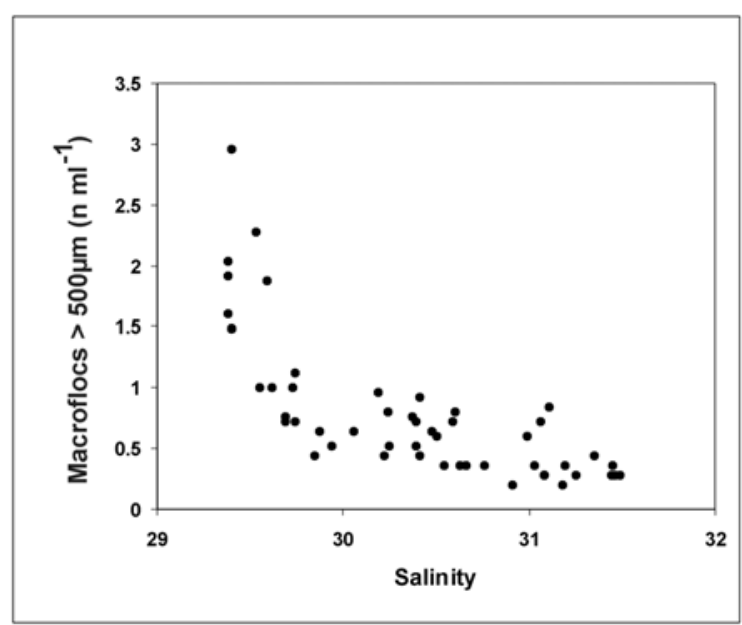

Figure 5: Relationship between number of macroflocs (ESD > 500 $\mu \mathrm{m})$ and salinity from the ebb-tidal cycle in the Elorn estuary.

\section{Vertical variability in particle populations}

The profiler was used onboard R/V Aranda (Finnish Inst. of Mar. Res.) during a field trip 19 to 29 July, 1999) at the entrance to the Gulf of Finland. This coastal zone is characterized by marked hydrodynamic activity. Horizontal and vertical salinity distributions in the area are indeed influenced by water exchange between the Baltic Sea and the Gulf of Finland (Pavelson et al., 1997). The cyanobacterial blooms that occur here and the spatial distribution 
of phytoplankton or zooplankton species can be explained by the water inflows from different origins (Kononen et al., 1996, 1999). The main objective of this work was to describe vertical particle distribution at moored stations and its variability over time in order to guide biological sampling. The ultimate aim of the study was to relate particle populations to the physical field at small scale and, more specifically, to turbulent kinetic energy dissipation (Kononen et al., in press). 25 profiles were realised. Data and video treatments from one representative profile performed at the anchor station ANCH2 (59 42’05N, 02337'65E; 50 meters depth) is studied and presented hereafter.

Results from CTD-FLUO profile indicate that the water column was stratified with a thermocline around $12 \mathrm{~m}$ (Fig. 6). Fluorescence was maximum in the upper layer (Fig. 6), corresponding to high abundance of small phytoplankton species $(4-8 \mu \mathrm{m})$. The latter were associated to decaying cyanobacteria colonies on the upper mixed layer as determined from water samples counts. The relationship between small volume particles (ESD $<10 \mu m$ ), volume measured by the PSA and fluorescence confirms the contribution of these small particles to the fluorescence peak (Fig. 7). However, the data cluster identified on figure 7, corresponding to the measurements performed below $40 \mathrm{~m}$, highlights the presence of a specific particle population containing no fluorescent pigments in this deep layer (40-50 m).

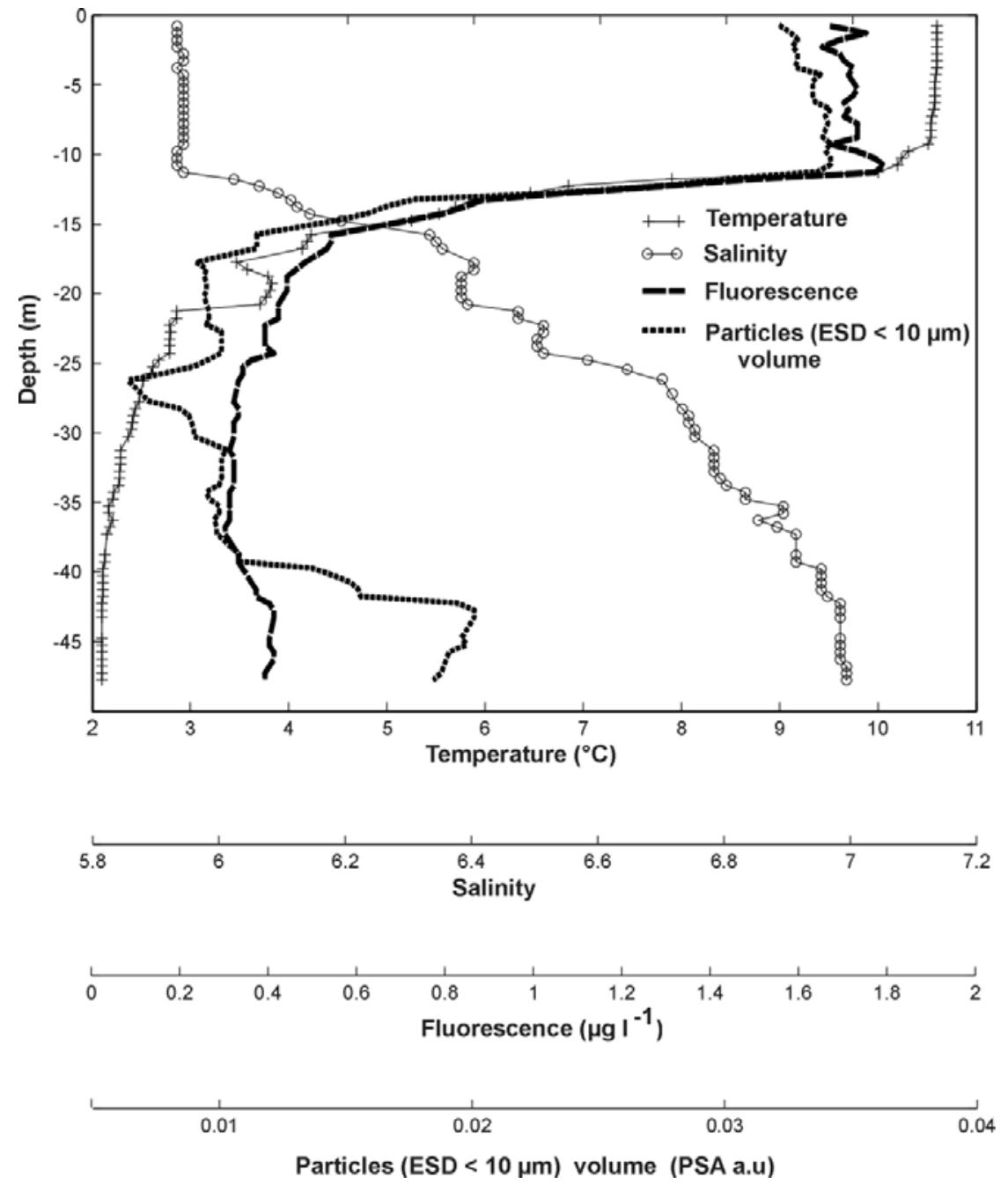

Figure 6: Vertical profiles from the Gulf of Finland concerning temperature ( ), salinity (O), fluorescence (--) and small particle volume (') . 


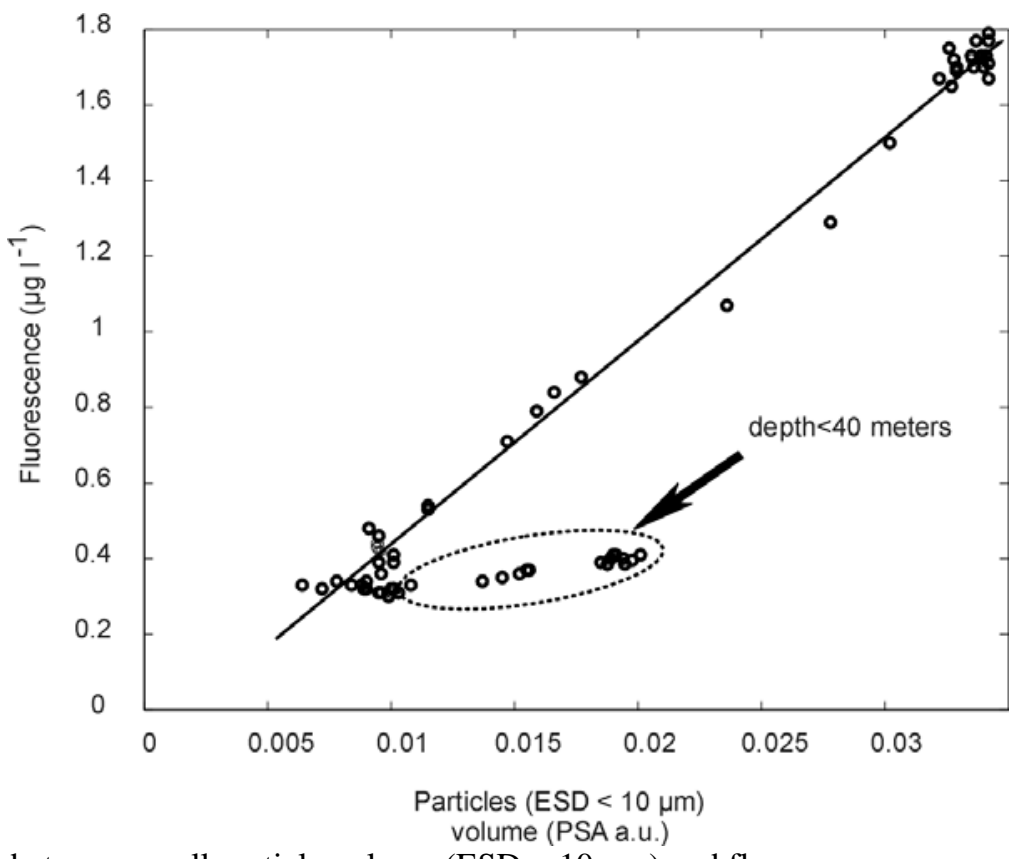

Figure 7: Relationship between small particle volume (ESD $<10 \mu \mathrm{m})$ and fluorescence.

Observation and image analysis from the video-system allowed the determination of four distinct layers with specific particles populations:

1. $\mathrm{Z}>40 \mathrm{~m}$ : On board video analyses revealed the presence of numerous small particles at 40$45 \mathrm{~m}$ depth; MGLV was high (data not shown) and a large number of small particles $(<200 \mu \mathrm{m})$ was detected (Fig. 8.b) below $40 \mathrm{~m}$. Sampling and microscopic observations from this layer revealed the presence of heterotrophic flagellates associated with large amounts of aggregates and detritus.

2. 11-40 m: few particles.

3. 8-11 m: located above the thermocline, this layer was interesting because of the abundance of zooplankton. Up to 7 copepods were simultaneously observed in the depth of field (12 $\mathrm{ml})$. Taking into account a possible bias due to phototropism in the box, the concentration was estimated between 60 and 600 animals $\mathrm{l}^{-1}$. Such thin layers, with abundance of copepods found above the density discontinuities in the water column, were also described by research teams using video techniques (Tiselius, 1998; Widder et al., 1999). More over, Cercopagis pengoi, an invasive Baltic cladoceran species was also detected from in situ video observations.

4. 0-8 m: the large particles present in the top layer (Fig. 8.c) are mainly colonies of cyanobacteria (Fig. 9). At this depth, the occurrence of large particles leads to the observation of high particle volume value (Fig. 8.a), although particle concentration is rather small.

Another limit of the video-systems appears here: due to the chosen particle resolution limit, it was not possible to resolve for particles smaller than $65 \mu \mathrm{m}$; this excludes the majority of phytoplankton species. However, during profile in coastal areas, the association of PSA and fluorometer on the custom profiler enables the detection an quantification of small particles populations including phytoplankton rich layers. In this configuration, the video-system seems more appropriate for the investigation of largest particles as zooplankton, cyanobacteria colonies or aggregates in the water column. 

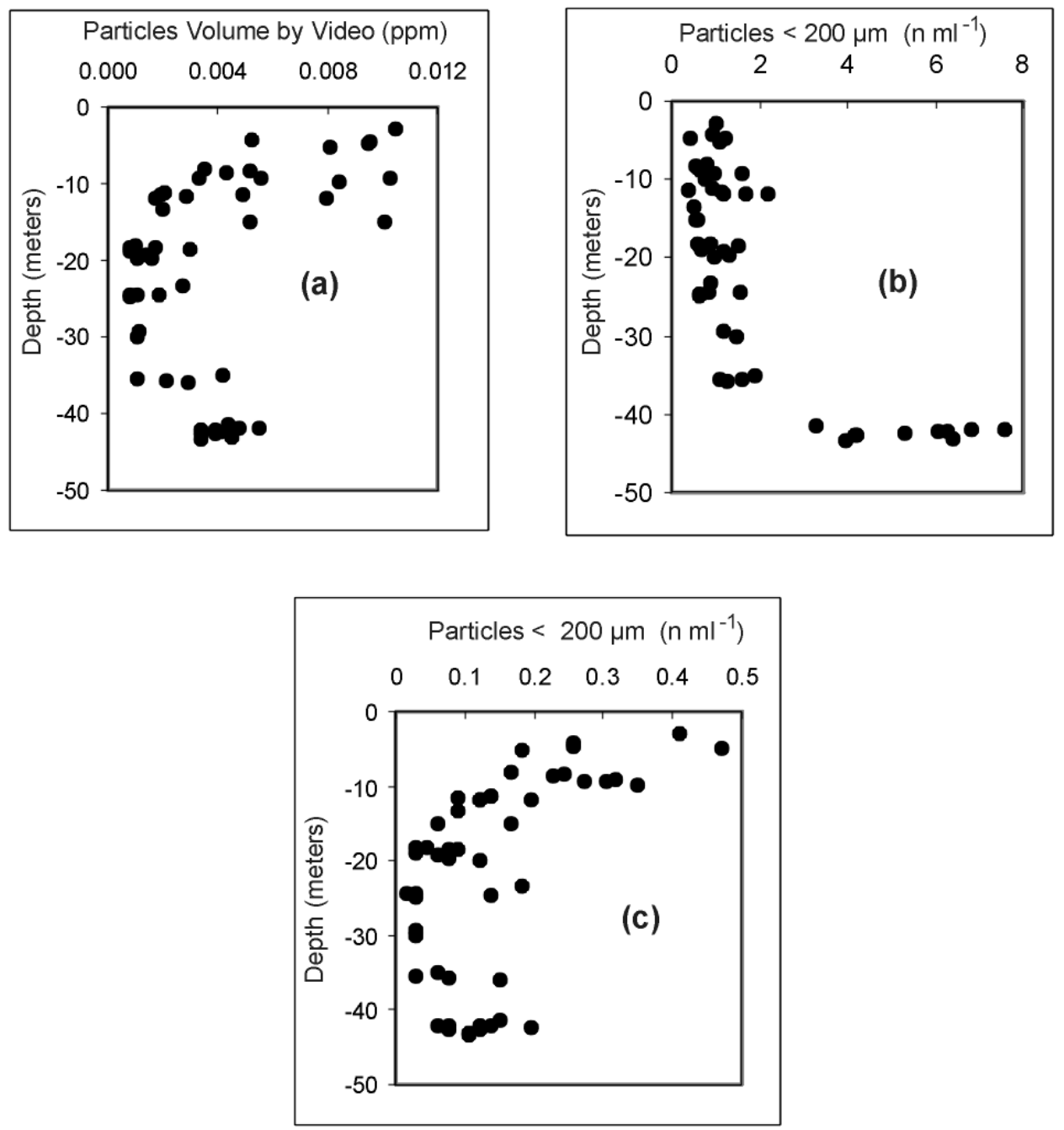

Figure 8: Results from the image analyses from a vertical profile in the Gulf of Finland. (a): Particles volume obtained by video. (b): Concentration of particles $<200 \mu \mathrm{m}$. (c): Concentration of particles $>200 \mu \mathrm{m}$.

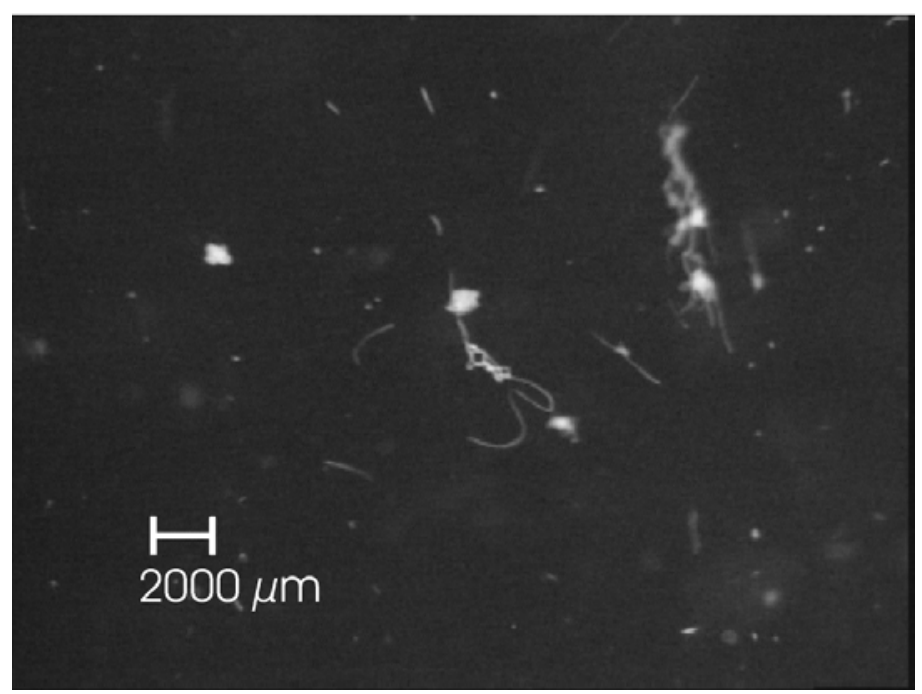

Figure 9: In situ representative image from 4.6 meters depth showing colonies of cyanobacteria. 
To conclude, it appears that the deployment of this custom profiler in an estuarine environment, where sediment concentration and particle size show wide distributions, has allowed the validation of a new video-system based on the Capture/Stilling Chamber. The limitation in particle sizing by the optical design has also been assessed. The reliability of the video treatments was dependent on the suspended sediment concentration and on the degree of flocculation. The video-system can resolve particle populations at concentrations lower than $25 \mathrm{mg} \mathrm{l}^{-1}$. The particle aggregation period detected by the PSA was also reliably described by the video-system. In coastal areas, both systems appeared to be useful to characterize particle populations. The particle sizer quantified the largest particles above $11 \mathrm{~m}$ and the video allowed the discrimination between zooplankton and cyanobacteria colonies. This system is therefore able to acquire sufficiently detailed information to provide insights on the basic principles of particle aggregation in coastal areas.

Association of both methods (video and diffraction) on the profiler enables the description of a precise size distribution for finest particles $(0.7-400 \mu \mathrm{m})$ by laser diffraction and the visualisation and the quantification of the largest ones $(>65 \mu \mathrm{m})$ by video. Direct observation by underwater video techniques provides reliable results, allowing the data validation by analytical methods such as in situ particle size distribution by diffraction analysis. Images are important sources of information for interpretation and analysis. Computers can reliably automate in real time the extraction of useful information such as morphometric measurement and size spectra classification through the use of digital image processing. For the next years, technologic developments in optics, laser lights and image analyses will lead to the appearance of new systems enabling improvements in the study of sedimentation and flocculation processes in estuaries. It will also help further understandings of the complex mechanisms which lead to the accumulation of living organisms in thin layers of coastal waters (“patches”; Leising, 2001; Seuront \& Lagadeuc, 2001).

\footnotetext{
Aknowledgments

The study was funded by the EU MAST3 MITEC, contract MAS3-CT97-0114. The development, construction and testing of the video-system was supported through IFREMER (French Research Institute for Exploitation of the Sea ). Thanks are due particularly to Michel Le Haitre for encouraging this work. The authors would also like to thank the two anonymous reviewers for their corrections and recommendations improving the manuscript. Very useful comments on the manuscript were also made by Dr. Dorothée Vincent.
} 


\section{References}

Agrawal, Y.C. \& Pottsmith, H.C. 1989 Autonomous long-term in situ particle sizing using a new laser diffraction instrument. Proceedings Oceans 89 3, 1575-1580.

Akiba, T. \& Kakui, Y. 2000 Design and Testing of an Underwater Microscope and Image Processing System for the Study of Zooplankton Distribution. IEEE Journal of Oceanic Engineering 25, 97-104.

Bale, A.J. \& Morris, A.W. 1987 In situ measurements of particle size in estuarine waters. Estuarine Coastal and Shelf Science 24, 253-263.

Bale, A.J. 1996 In situ Laser Optical Particle Sizing. Journal of Sea Research 36 (1/2),31-36. Conner, C.S. \& De Visser, A.M. 1992 A laboratory investigation of particle size effects on an optical backscatterrance sensor. Marine Geology 108, 151-159.

Davis, C.S., Gallager, S.M., Marra, M. \& Stewart, W.K. 1996 Rapid visualization of plankton abundance and taxonomic composition using the Video Plankton Recorder. Deep Sea Research 43, 1947-1970.

Dekshenieks, M.M., Donaghay, P.L., Sullivan, J.M., Rines, J.E.B., Osborn, T.R. \& Twardowski, M.S. 2001 Temporal and spatial occurrence of thin phytoplankton layers in relation to physical processes. Marine Ecology Progress Series 223, 61-71.

Dyer, K.R. \& Manning, A.J. 1999 Observation of the size, settling velocity and effective density of flocs and their fractal dimensions. Journal of Sea Research 41, 87-95.

Eisma D. 1986 Flocculation and de-flocculation of suspended matter in estuaries. Netherlands Journal of Sea Research 20, 183-199.

Eisma, D., Schuhmacher, T., Boekel, H., Van Heerwaarden, J., Franken, H., Lann, V., Vaars, A., Eijgenraam, F. \& Kalf, F. 1990 A camera and image analysis system for in situ observation of flocs in natural waters. Netherlands Journal of Sea Research 27, 43-56.

Eisma, D. \& Li, A. 1993 Changes in suspended-matter floc size during the tidal cycle in the Dollard estuary. Netherlands Journal of Sea Research 31(2), 107-117.

Fennessy, M.J., Dyer, K.R. \& Huntley, D.A. 1994 INSSEV : An instrument to measure the size and settling velocity of flocs in situ. Marine Geology 117, 107-117.

Francks, P.J S. \& Jaffe, J. 2001 Microscale distribution of phytoplankton : initial results from a two-dimensional imaging fluorometer, OSST. Marine Ecology Progress Series 22, 59-72.

Gentien, P., Lunven, M., Le Haitre, M. \& Duvent, J.L. 1995 In situ depth profiling of particle sizes. Deep Sea Research 42, 1297-1312.

Gibbs, J.R. \& Wolanski, E. 1992 The effects of flocs on optical backscattering measurements of suspended material concentration. Marine Geology 107, 289-291.

Gorsky, G., Aldorf, C., Kage, M., Picheral, M., Garcia, Y. \& Favole, J. 1992 Vertical distribution of suspended aggregates determined by a new underwater video profiler. Annales Institut Oceanographiques, Paris 68, 275-280.

Gorsky, G., Picheral, M. \& Stemmann, L. 2000 Use of the Underwater Video Profiler for the Study of Aggregate Dynamics in the North Mediterranean. Estuarine, Coastal and Shelf Science 50,121-128.

Jago, C.F \& Bull, C.F.J. 2000 Quantification of errors in transmissometer-derived concentration of suspended particulate matter in the coastal zone: implications for flux determinations. Marine Geology 169, 273-286

Katz, J., Donaghay, P.L., Zhang, J., King, S. \& Russell, K. 1999 Submersible holocamera for detection of particle characteristics and motions in the ocean. Deep Sea Research. 46. p. 14551481.

Knowles, S.C. \& Wells, J.T. 1996 In situ aggregate analysis camera (ISAAC): A quantitative tool for analyzing fine-grained suspended material. Limnology and Oceanography 43, 19541962. 
Kononen, K., Kuparinen, J., Makela, K., Laanemets, J., Pavelson, J. \& Nommann, S. 1996 Initiation of cyanobacterial blooms in a frontal region at the entrance to the Gulf of Finland, Baltic Sea. Limnology and Oceanography 41, 98-112.

Kononen, K., Huttunen, M., Kanoshina, I., Laanemets, J., Moisander,P. \& Pavelson, J. 1999 Spatial and temporal variability of a dinoflagellate-cyanobacterium community under a complex hydrodynamical influence: A case study at the entrance to the Gulf of Finland. Marine Ecology Progress Series 186, 43-57.

Kononen, K., Gentien, P., Lunven, M., Huttula, T., Laanemets, J., Stips, A., Huttunen, M., Lilover, M., Hallfors, S. \& Pavelson, J. 2003 Development of a deep chlorophyll maximum of Heterocapsa triquetra Ehrenb at the entrance to the Gulf of Finland. Limnology and Oceaonography, In Press.

Kranck K. 1973 Flocculation of suspended sediment in the sea. Nature 246, 348-350.

Lunven, M. \& Gentien, P. 2000 Suspended sediment in a macrotidal estuary : comparison and use of different sensors. Oceanologica Acta 23-3, 245-260.

Leising A. W. (2001) Copepod foraging in patchy habitats and thin layers using a 2-D individual-based model. Marine Ecology Progress Series 216, 167-179.

Milligan, T.G. 1996 In situ particle (floc) size measurements with the Benthos 373 plankton silhouette camera. Journal of Sea-Research 36, 93-100.

Owen, R.W.1989 Microscale and finescale variations of small plankton in coastal and pelagic environments. Journal of Marine Research 47, 197-240.

Pavelson, J., Laanemets, J., Kononen, K. \& Nommann, S. 1997 Quasi-permanent density front at the entrance to the Gulf of Finland : response to wind forcing. Continental Shelf Research 17, 3, 253-265.

Seuront, L. \& Lagadeuc, Y. (2001) Multiscale patchiness of the calanoid copepod Temora longicornis in a turbulent coastal sea. Journal of Plankton Research 23, 1137-1145.

Tiselius, P. 1998 An in situ video camera for plankton studies : deisgn and preliminary observations. Marine Ecology Progress Series 164, 293-299.

Trent, J.D., Shanks, A.L. \& Silver, M.W. 1978 In situ and laboratory measurements on macroscopic aggregates in Monterey Bay, California. Limnology and Oceanography 23, 626635.

Van Leussen, W. \& Cornelisse, J. 1996 The Underwater Video system VIS. Journal of Sea Research 36(1/2), 77- 81.

Vilivic, D., Legovic, T. \& Zutic, V. 1989 Vertical distribution of phytoplankton in a stratified estuary. Aquatic Sciences 51, 31-46.

Widder, E.A., Johnsen, S., Bernstein, S.A., Case, J.F. \& Neilson, D.J. 1999 Thin layers of bioluminescent copepods found at density discontinuities in the water column. Marine Biology 134 , 429-437. 